\title{
Comparative phytochemical evaluation of natural and micropropagated plants of Bacopa monnieri (L.)
}

\author{
Firoj A. TAMBOLI ${ }^{1 *}$, Vinod D. RANGARI ${ }^{2}$, Suresh G. KILLEDAR ${ }^{1}$, Sagar U. JADHAV ${ }^{1}$, Trupti S. GHATAGE ${ }^{3}$, Vishwajeet P. KORE \\ Department of Pharmacognosy, Bharati Vidyapeeth College of Pharmacy, Kolhapur (M.S.) India \\ 2 Department of Pharmacognosy, S.L.T. Institute of Pharmaceutical Sciences, Guru Ghasidas Vishwavidyalaya (Central University), Koni, Bilaspur - 495009 (CG) India. \\ 3 Department of Pharmaceutical Sciences, Rashtrasant Tukadoji Maharaj Nagpur University, Nagpur, India.
}

\begin{abstract}
Bacopa monnieri Linn. an important medicinal plant of Scrophulariaceae family and is distributed in the wet and marshy lands throughout India, Nepal, Sri Lanka, China, Taiwan, and Hawaii. It is endangered species so it is necessary to preserve germplasm. The objective of this research work is the comparative phytochemical evaluation of natural and micro-propagated plants of Bacopa monnieri (BM). It shows the presence of various phytoconstituents namely, alkaloids, saponins, phenolics, and flavonoids. These phytoconstituents are responsible for anti-oxidant and various other activity of the plant. The protocols for tissue culture has been developed for regeneration of the BM plant from small part (nodal segment). The regenerated plant having the similar potential in terms of phytoconstituents. The protocols of Murashige and Skoog medium can be used for the clonal regeneration of plant on the large scale through which it can be protected and preserved for the long duration in small space. From the comparative phytochemical investigation by HPTLC, the phytoconstituents which occur in the micro propagated plant are similar to that of the natural plant of $B$. monnieri.
\end{abstract}

KEYWORDS: Bacopa monnieri Linn., flavonoids, HPTLC, Micropropagation, Brahmi.

\section{INTRODUCTION}

Now days the plant tissue culture techniques are more commonly used for the investigations of the secondary metabolites. Already 2000 plants have been reported to be regenerated through the plant tissue culture. It has also been shown that many of such plants can produce secondary metabolites in culture. The method is based on using a plant part or single cell or tissue segment in artificial aseptic conditions is called "Tissue Culture" and these help without affecting the main feature of plants or herbs. Tissue culture technology has been known as an effective tool to propagate several valuable medicinal plants. Therefore now plant tissue culture has been included as an important tool under biotechnology. The nutritional requirements and metabolic activities of cells culture are essentially similar for all cells lines, regardless of the species tissues of origin. A source of carbohydrate is essential and usually, sucrose or inositol is used in high percentage. The inorganic salt complex includes calcium, magnesium, and potassium as microelements and manganese, boron, copper, molybdenum and cobalt as microelement, iron are supplied in the form of EDTA complex, nitrogen as nitrates. The other microelements are sulfur, ammonium, phosphates and chlorides as salts. Several vitamins of $\mathrm{B}$ group and growth regulators are added. The medium is completed by the addition of coconut water and

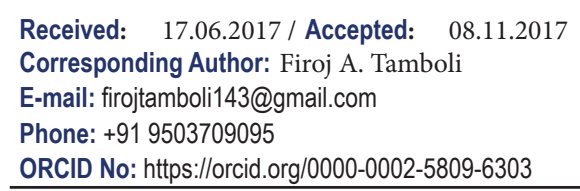

solidified if necessary with agar. Various environmental factors affecting plant tissue culture are temperature, hydrogen ion concentration and light [1-4].

Bacopa monnieri is a highly valuable medicinal plant from the Scrophulariaceae family has been proven its importance majorly in relation to botanical, commercial, ethnopharmacological, phytochemical, pharmacological and toxicological studies. It is distributed in the wet and marshy lands throughout India, Nepal, Sri Lanka, China, Taiwan, and Hawaii. It shows the presence of alkaloids (nicotine, brahmin, herpestine), saponins (hersaponin, betulic acid and bacosides) and other chemicals like stigmastanol, betasitosterol, and stigmasterol. It is found to be effective in several neurological disorders like anxiety and neurosis. It is also used in anti-inflammatory, antioxidant, analgesic and antipyretic activity, treat asthma, insanity, epilepsy, hoarseness, enlargement of spleen, snake bite, rheumatism, leprosy, eczema and ringworm, it is also used as a diuretic, appetitive and cardio tonic [5-9].
How to cite this article: Tamboli FA, Rangari VD, Killedar SG, Jadhav SU, Ghatage TS, Kore VP. Comparative phytochemical evaluation of natural and micropropagated plants of Bacopa monnieri (L.). Marmara Pharm J. 2018; 22 (1): 66-73. 


\section{RESULTS}

\subsection{Extraction and extractive value}

Table 1. Extractive values of various extracts of B. monnieri

\begin{tabular}{|c|c|c|c|c|}
\hline Sr. No. & Crude drug & Extract & Total Extract $(\mathrm{g})$ & $\%$ yield \\
\hline 1. & \multirow{2}{*}{$\begin{array}{l}\text { B. monnieri natural plant } \\
\text { material (BMN) }\end{array}$} & Chloroform & 6.73 & 6.73 \\
\hline 2. & & Ethanol & 11.0 & 11.0 \\
\hline 3. & \multirow{2}{*}{$\begin{array}{l}\text { B. monnieri callus material } \\
\text { (BMC) }\end{array}$} & Chloroform & 0.33 & 2.2 \\
\hline 4. & & Ethanol & 0.50 & 3.33 \\
\hline 5. & \multirow{2}{*}{$\begin{array}{l}\text { B. monnieri propagated plant } \\
\text { material (BMM) }\end{array}$} & Chloroform & 2.5 & 1.08 \\
\hline 6. & & Ethanol & 6.0 & 2.6 \\
\hline 7. & B. monnieri standard & Chloroform & 3.0 & 10.7 \\
\hline 8. & "Memory plus" (BMS) & Ethanol & 4.0 & 14.2 \\
\hline
\end{tabular}

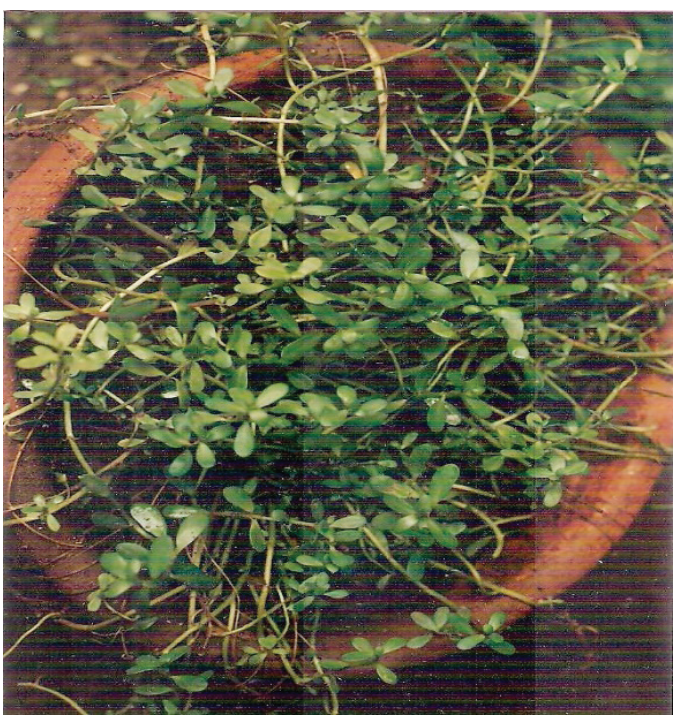

Figure 1. Bacopa monnieri Natural plant

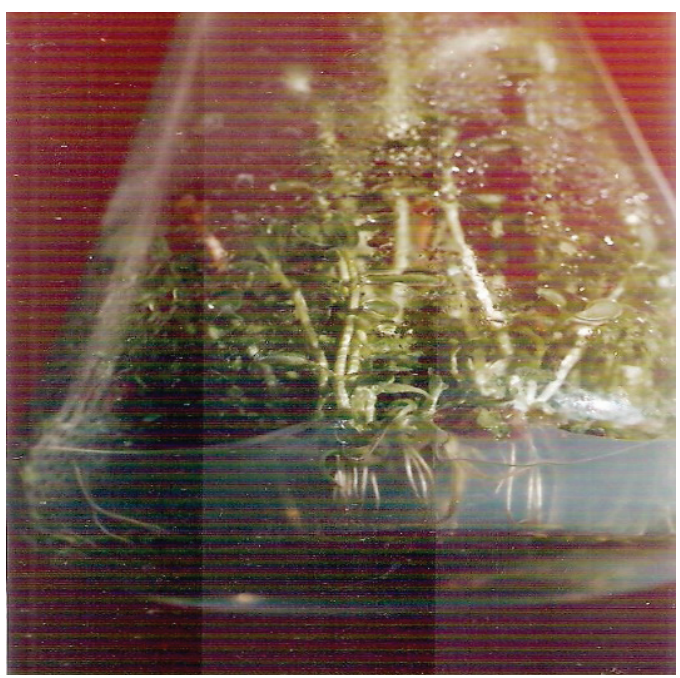

Figure 2. Bacopa monnieri micro propagated plant

\subsection{Isolation of bacosides and other fractions from the Bacopa monnieri}

General procedure for the isolation of bacosides and other fractions from the extracts of B. monnieri are as follows: All the ethanolic extracts were concentrated. Concentrated ethanolic extract, dissolved in $60 \%$ ethanol. This solution extracted in separating funnel with benzene to yield - Ethanol extract (x) and Benzene extract (y). During concentration of ethanolic extract $(\mathrm{x})$ a viscous slimy; material precipitated out which was separated from the supernatant $(\mathrm{z})$. The slimy mass was dissolved in alcohol and fractionally precipitated with ether and pet. Ether repeatedly leading to the separation of brown resinous material. The alcohol-ether petroleum ether solution was concentrated and the residue was macerated with acetone and filtered. The acetone insoluble powder was partitioned between butanol and water. During concentration of the butanol solution, a precipitate settled down which was filtered (FI). The filtrate was again concentrated and precipitated with acetone and ether which yielded a powder (FII). The mother liquor was concentrated to dryness when a brownish powder (FIII) was obtained. The acetone soluble fraction was left in the cold for several days when a solid settled down which was filtered and washed with acetone. (FIV). The filtrate was concentrated almost to dryness and the hygroscopic, resinous material was macerated with ethyl acetate and the solvent washings were added to the benzene solution (y). From the above, procedure bacoside A (F I, F II, F III), and bacoside B (FIV), were obtained. These fractions were further confirmed by the paper chromatography study of the isolated fractions and its comparison with the literature.

Solvent system: Ethyl acetate: pyridine: water (4:1:1)

Developing reagent: Trichloroacetic acid (25\%) in chloroform solution.

\subsection{HPTLC study}

HPTLC studies of all the extracts and fractions were done by HPTLC (Figure 3, Figure 4, Figure 5, Figure 6, and Figure 7). 


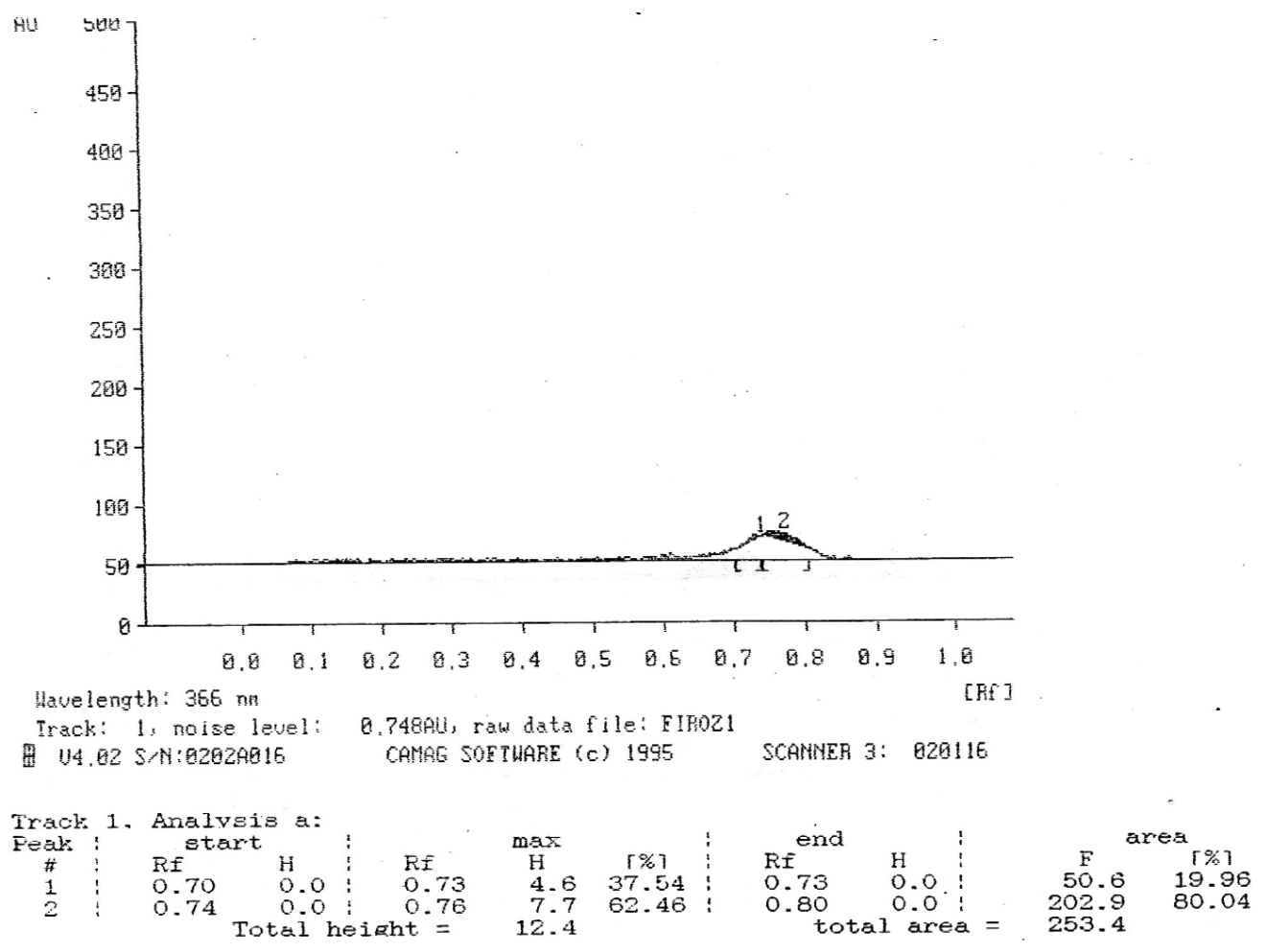

Figure 3. HPTLC Chromatogram

Sample: Fraction I of ethanolic extract of B. monnieri Natural (BMN) plant Mobile phase: Ethyl acetate: Pyridine: Water (4:1:1)

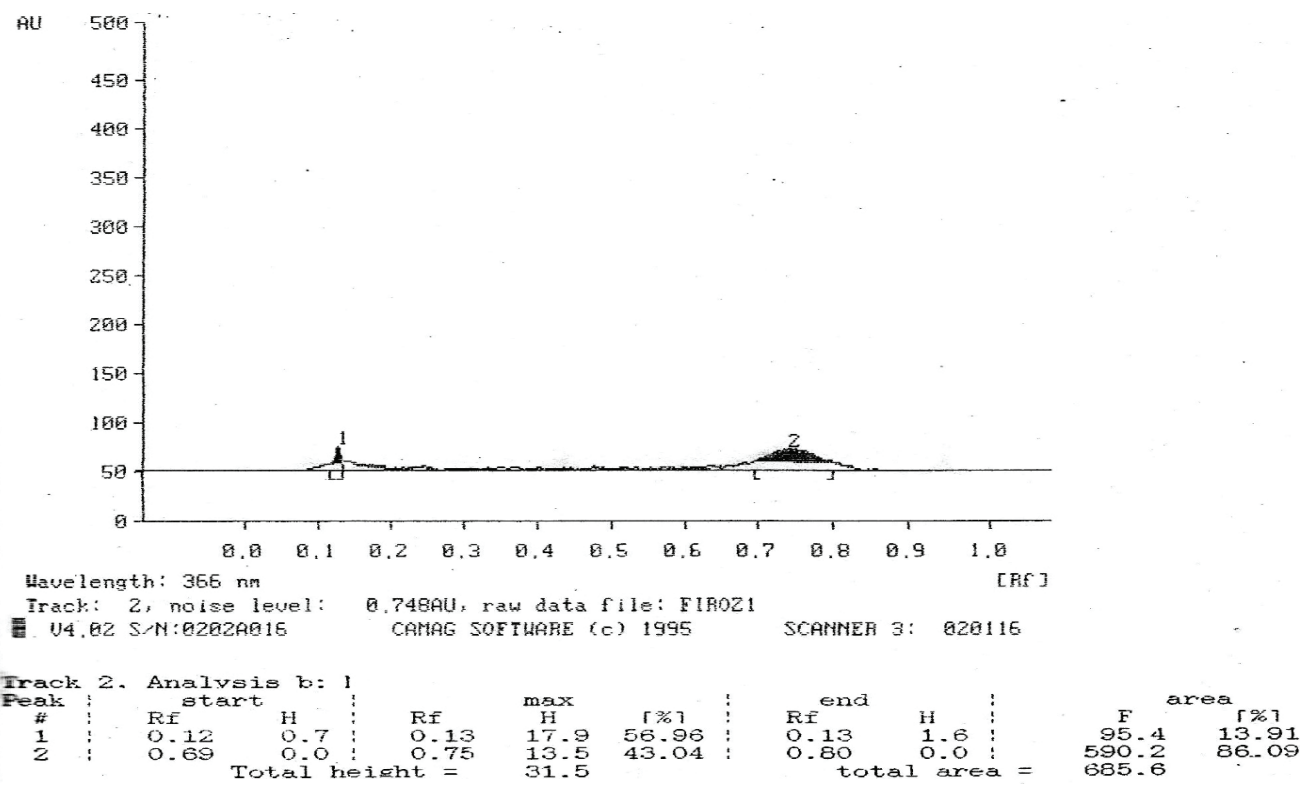

Figure 4. HPTLC Chromatogram

Sample: Fraction I of ethanolic extract of B. monnieri Micropropagated (BMM) plant Mobile phase: Ethyl acetate: Pyridine: water (4:1:1) 


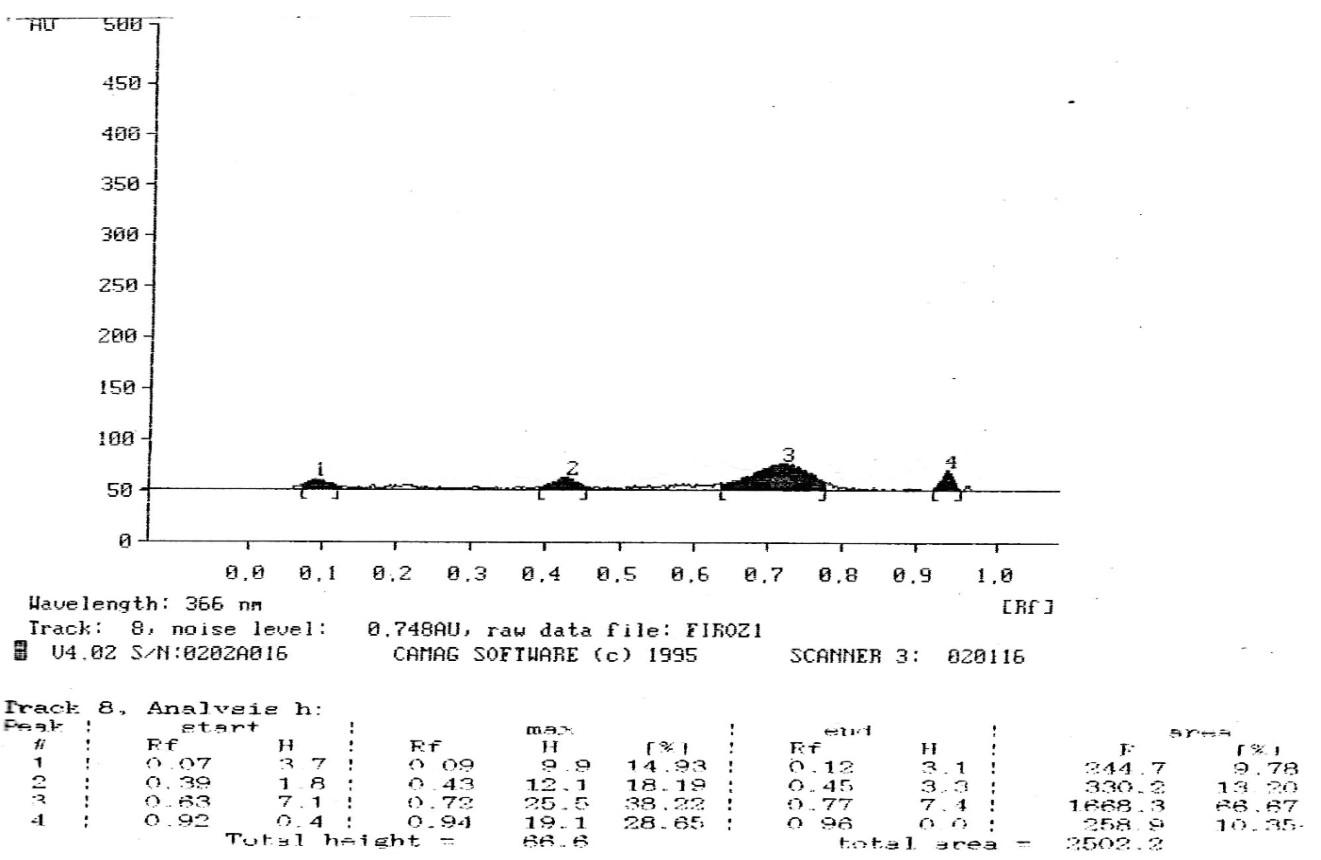

Figure 5. HPTLC Chromatogram

Sample: Fraction II of ethanolic extract of B. monnieri Micropropagated (BMM) plant Mobile phase: Ethyl acetate: Pyridine: water (4:1:1)

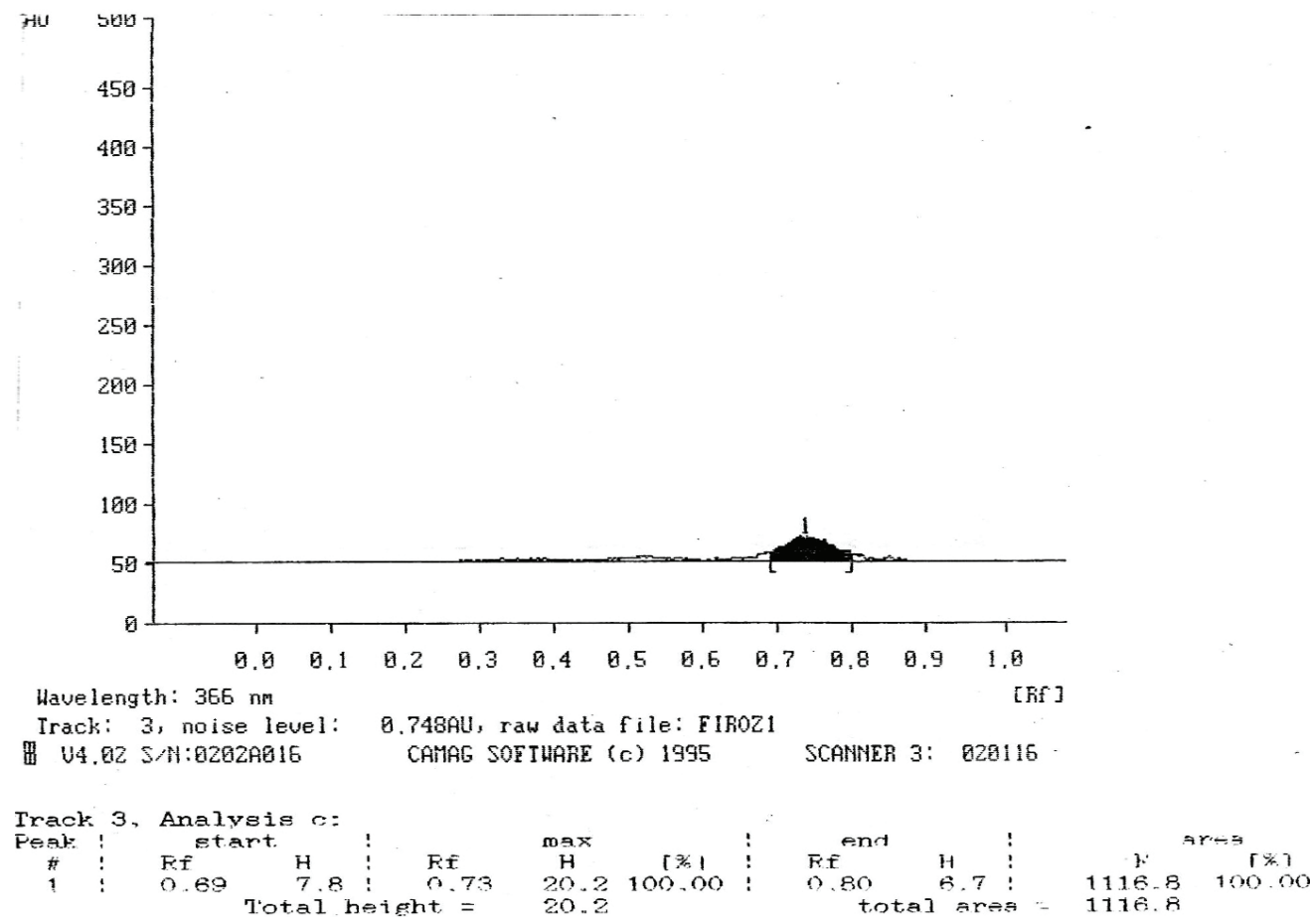

Figure 6. HPTLC Chromatogram

Sample: Fraction I of ethanolic extract of B. monnieri Standard (BMS) plant

Mobile phase: Ethyl acetate: Pyridine: water (4:1:1) 


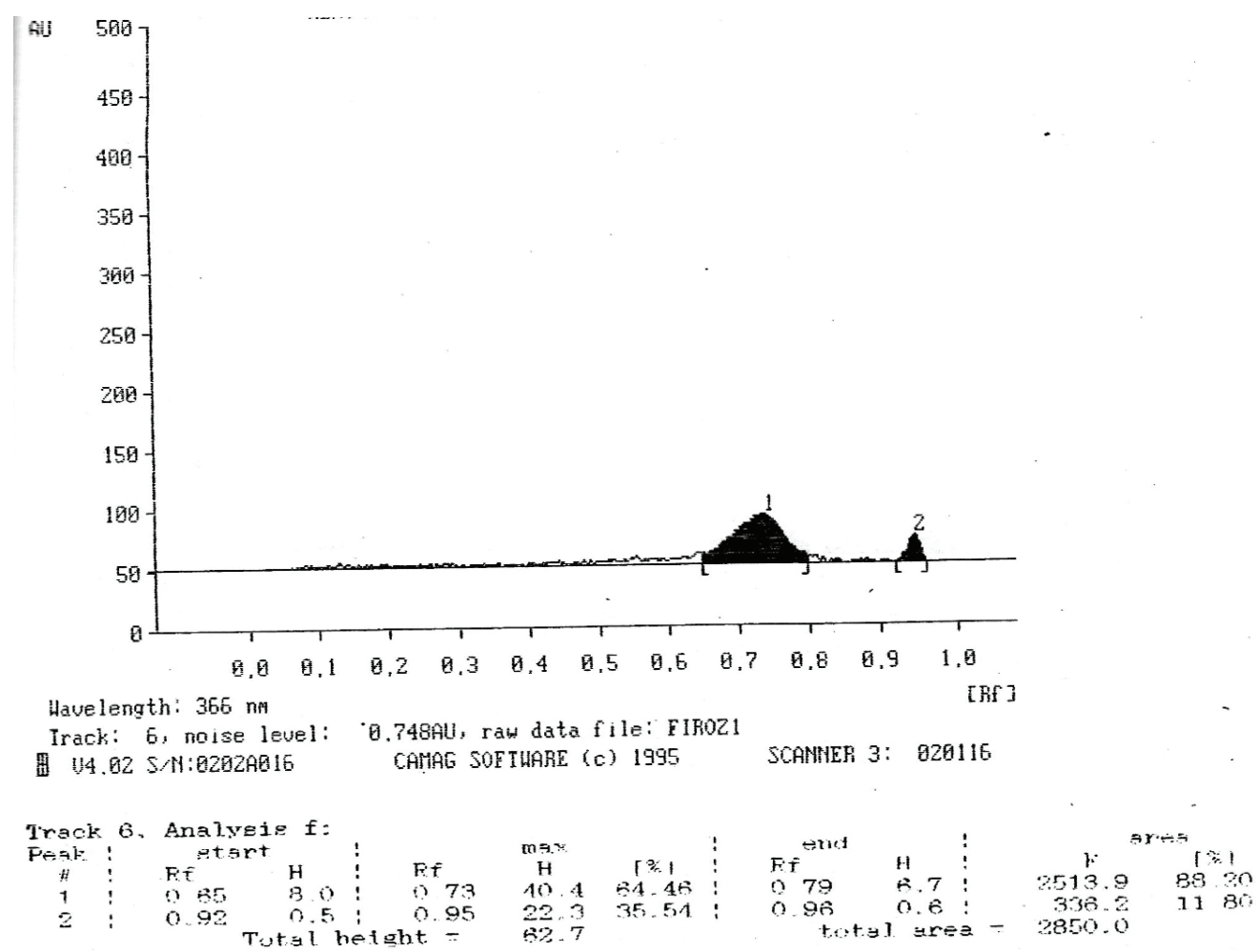

Figure 7. HPTLC Chromatogram

Sample: Fraction IV of ethanolic extract of B. monnieri Standard (BMS) plant

Mobile phase: Ethyl acetate: Pyridine: water (4:1:1)

\section{DISCUSSION}

In this, comparative phytochemical evaluation of natural and micro propagated plant of $B$. monnieri was carried out. The extraction of B. monnieri natural (BMN) plant, B. monnieri Callus (BMC), B. monnieri micro-propagated (BMM) plant, B. monnieri Standard (BMS) ("Memory Plus") samples of crude drugs and their formulation were carried out with chloroform and ethanol. The extractive values of chloroform extracts of BMN, BMC, BMM and BMS were $6.73,2.2,1.08$ and 10.7 percent respectively. The extractive value of the ethanolic extracts of BMN, BMC, BMM and BMS were $11,3.33,2.6$ and 14.2 percent respectively. The extractive value of the chloroform extract of BMS showed a higher percentage than that of BMN, BMC and BMM. Similarly, an extractive value of ethanolic extract of BMS showed the higher value than that of BMN, BMC and BMM. A systematic study of the extracts of $B$. monnieri was undertaken on the aspects namely thin layer chromatography of all the extracts, isolation of constituents by literature procedure, identification of constituents by paper chromatography with reference standard paper chromatography, HPTLC studies. Studies of all the extracts and fractions were done by HPTLC. According to the literature $1.54 \%$ percent bacoside A was isolated from the crude drug B.monnieri. If we consider this as a standard value, the bacoside A percent by HPTLC for the micropropagated plant seems to be quite higher (bacoside A $5.1 \%$ ) than that of naturally grown strain (bacoside $3.9 \%$ ) by the calculation of area under the curve.Indicated the presence of one-two additional peaks in the micropropagated plant extract (BMM) (Figure 4,5). These additional peaks seem to be due to the change of plants natural condition to that of controlled aseptic conditions. The total micropropagated plant material (about $23 \mathrm{~g}$ dry weight basis) was obtained during 1 year.

\section{CONCLUSION}

A conclusion may be withdrawn from the present comparative phytochemical investigation that, the phytoconstituents which occur in the plant produced by the tissue culture technique i.e. micro propagated plant are similar to that of the natural plant of B. monnieri. But there are extra constituents found along with the major constituents present in the natural plant, as found by HPTLC studies. The percent yield of bacoside A obtained in the micro propagated plant is that $5.1 \%$ while the natural plant 
is $3.9 \%$ by HPTLC studies. Thus, biosynthesis of bacosides in the micro propagated plant seem to be accelerated in aseptic condition. This finding is encouraging for the further studies of the tissue culture studies on B. monnieri in varying nutrients and stress conditions.

\section{Materials and Methods}

\subsection{Selection of plants}

Bacopa monnieri is an herb of medicinal importance which has many proven beneficial pharmacological activity. Due to the pharmacological importance and commercial value of the plant, over exploitation from natural resources is taking place and putting this herb at the edge of endangered species.

\subsection{Collection and authentication of plant}

Plant of Bacopa monnieri was collected from the field of Jawaharlal Nehru Ayurvedic Medicinal Plant Garden and Herbarium Kothrud, Pune in the month of February and authenticate from same place. After collection plant material was washed thoroughly with water and kept for drying in the sunlight for 4-5 days. After drying, the plant material was broken into very small pieces and then passed through crusher mill, to obtain the coarse powder. The powder was passed through sieve no. $12[10,11]$.

\subsection{Development of micro-propagated tissue culture plant}

Shoot tips and nodal segments of $B$. monnieri L. were cultured on Murashige and Skoog's (M. S.) basal medium supplemented with different concentration of BAP and IAA as shown in Table 2 . A positive response was observed in nodal segments on medium containing BAP (2.5 mg/l). Regeneration of 3-4 cm long shoots was observed after 18-20 days. Further differentiation in callus at the base gave after 30-35 days of inoculation. As on rooting was observed the regenerated shoots were excised and transformed to white's medium supplemented with IAA ( $1 \mathrm{mg} / \mathrm{l})$ leading to initiation of rooting in 15-20 days and formation of complete plantlets. These plantlets were collected. After collection, the micro propagated plant material was washed with water to remove nutrient medium and then kept for drying in shade for 5-6 days. Dried plant material was broken into very small pieces, coarsely powdered and subjected to soxhlet extraction [12].

Table 2. Composition and preparation of Murashige and Skoog medium

\begin{tabular}{|c|c|c|c|c|}
\hline Constituents & Molarity in medium & $\begin{array}{l}\text { Concentration of stock } \\
\text { solution }\end{array}$ & $\begin{array}{l}\text { Volume of stock per liter of } \\
\text { medium }(\mathrm{ml})\end{array}$ & Storage of stock solution \\
\hline \multicolumn{5}{|c|}{ Major inorganic nutrients } \\
\hline $\mathrm{NH}_{4} \mathrm{NO}_{3}$ & $2.06 \times 10^{-2}$ & 33000 & \multirow{5}{*}{50} & \multirow{5}{*}{$+4^{\circ} \mathrm{C}$} \\
\hline $\mathrm{KNO}_{3}$ & $1.88 \times 10^{-2}$ & 38000 & & \\
\hline $\mathrm{CaCl}_{2} 2 \mathrm{H}_{2} \mathrm{O}$ & $3.00 \times 10^{-3}$ & 8800 & & \\
\hline $\mathrm{MgSO}_{4} 7 \mathrm{H}_{2} \mathrm{O}$ & $1.50 \times 10^{-3}$ & 7400 & & \\
\hline $\mathrm{KH}_{2} \mathrm{PO}_{4}$ & $1.25 \times 10^{-3}$ & 3400 & & \\
\hline \multicolumn{5}{|l|}{ Trace elements } \\
\hline KI & $5.00 \times 10^{-6}$ & 166 & \multirow{7}{*}{5} & \multirow{7}{*}{$+4^{\circ} \mathrm{C}$} \\
\hline $\mathrm{H}_{3} \mathrm{BO}_{3}$ & $1.00 \times 10^{-4}$ & 1240 & & \\
\hline $\mathrm{MnSO}_{4} \cdot 4 \mathrm{H}_{2} \mathrm{O}$ & $9.99 \times 10^{-5}$ & 4460 & & \\
\hline $\mathrm{ZnSO}_{4} 7 \mathrm{H}_{2} \mathrm{O}$ & $2.00 \times 10^{-5}$ & 1720 & & \\
\hline $\mathrm{Na}_{2} \mathrm{M}_{0} \mathrm{O}_{4} \cdot 2 \mathrm{H}_{2} 0$ & $1.00 \times 10^{-6}$ & 50 & & \\
\hline $\mathrm{CuSO}_{4} 5 \mathrm{H}_{2} \mathrm{O}$ & $1.00 \times 10^{-7}$ & 5 & & \\
\hline $\mathrm{CoCl}_{2} \cdot 6 \mathrm{H}_{2} \mathrm{O}$ & $1.00 \times 10^{-7}$ & 5 & & \\
\hline
\end{tabular}




\begin{tabular}{|c|c|c|c|c|}
\hline \multicolumn{5}{|l|}{ Iron source } \\
\hline $\mathrm{FeSO}_{4} 7 \mathrm{H}_{2} \mathrm{O}$ & $1.00 \times 10^{-4}$ & 5560 & & \multirow{2}{*}{$+4^{\circ} \mathrm{C}$} \\
\hline $\mathrm{Na}_{2}$ EDTA. $2 \mathrm{H}_{2} 0$ & $1.00 \times 10^{-4}$ & 7460 & & \\
\hline \multicolumn{5}{|c|}{ Organic supplement } \\
\hline Myo-inositol & $4.90 \times 10^{-4}$ & 20000 & \multirow{5}{*}{5} & \multirow{5}{*}{$-20^{\circ} \mathrm{C}$ (In $5 \mathrm{ml}$ aliquots) } \\
\hline Nicotinic acid & $4.66 \times 10^{-6}$ & 100 & & \\
\hline Pyridoxine $\mathrm{HCl}$ & $2.40 \times 10^{-6}$ & 100 & & \\
\hline Thiamine $\mathrm{HCl}$ & $3.00 \times 10^{-7}$ & 100 & & \\
\hline Glycine & $3.00 \times 10^{-5}$ & 400 & & \\
\hline \multicolumn{5}{|l|}{ Carbon source } \\
\hline Sucrose & $8.80 \times 10^{-2}$ & - & & \\
\hline
\end{tabular}

\subsection{Soxhlet Extraction}

Continuous hot percolation method was selected for extraction. The capacity of Soxhlet apparatus was 2.5 liters. The coarse powder of plant material was weighing $100 \mathrm{~g}$ which were taken in a thimble made of filter paper. Qualigens XLR grade chloroform was distilled and used for the extraction. The thimble was allowed to siphon and then again solvent was added to side tube level and kept for one day with the drug contact. Then the process was started after addition of some porcelain pieces to avoid bumping and it was continued for 8 hours. Before heating it once again on the next day, the assembly was detached and the menstrum was shaken. The process was continued until the siphoned solvent showed no spot over the paper. The marc was removed and dried in shade at room temperature. The solvent was recovered by the distillation process. The dried marc/ defatted material was extracted with ethanol using the same condition followed by chloroform extraction.

Similarly the extraction of the callus and micro-propagated plants of B. monnieri and standard "Memory plus" was done with chloroform and ethanol to get the respective extract.

\subsection{Thin Layer Chromatography}

Thin layer chromatography (TLC) of B. monnieri was performed by using Silica gel $G$ as a stationary phase. The choice of mobile phase depends upon nature of phytoconstituents. Standard borosil glass capillaries were used for applying samples on the prepared plates. The spot was applied at $1 \mathrm{~cm}$ from the end of the plate. The prepared plates were air dried and then activated in the oven at $105^{\circ} \mathrm{C}$ for 30 minutes. The plates were initially observed under UV radiation and colour fluorescence was noted. It was then kept in iodine chamber. After observing the spots the parameter noted were Rf value, colour, and its intensity $[13,14]$.

\subsection{Paper Chromatography}

This technique is a type of partition chromatography in which the substances are distributed between two liquids one is the stationary liquids which are held in the fibers of the paper and the other is a mobile phase. Whatman filter paper was used. Glass capillary was used for application of the sample. The paper was dipped in the chamber in such that the spot was not dipped completely into the solvent system. After development, the paper was taken out of chamber carefully. Paper chromatogram was dried by hot air. The spraying reagent trichloroacetic acid in chloroform solution was used and a spot was recorded [15].

\subsection{High-performance thin layer chromatography}

HPTLC can simultaneously handle several samples even of divergent nature and composition supporting several analysts at a given time. HPTLC are coated plates, Silica gel $60 \mathrm{~F}_{254}$ - Aluminium. The sample was prepared in ethanol. The concentration of the solution was kept as $1 \mathrm{mg} / \mathrm{ml}$. Linomat IV sample applicator was used for the sample application. $10 \mu \mathrm{l}$ of all fractions soluble in ethanol were applied on HP plate from about $1 \mathrm{~cm}$ edge of HP plate using a bandwidth of $6 \mathrm{~mm}$ and the distance between tracks $5 \mathrm{~mm}$. The plates were kept in twin trough chambers and care was taken that solvent system level was below that of bands. The plate was 
then removed from the chamber and dried by hot hand dryer. The plates were initially observed under UV radiation. For detection TLC scanner III was used. All the tracks were scanned at a different wavelength [16-19].

\section{Acknowledgements}

Authors are thankful to Principal Dr. H. N. More for providing the facilities for the works.

\section{Authorship statement}

Author contributions: Concept -F.T., V.R.; Design -F.T., V.R.; Supervision -V.R.; Resource -F.T., V.R.; Materials -V.R., F.T.; Data Collection and/or Processing - S.J., T.G., V.K., S.K.; Analysis and/or Interpretation - S.K., S.J., T.G., V.K.; Literature Search -F.T., S.K., S.J., T.G., V.K.; Writing -F.T., S.K., S.J., T.G., V.K.; Critical Reviews -V.R., S.K., F.T., S.J., T.G., V.K.

\section{Conflict of interest statement}

The authors declared no conflict of interest.

\section{REFERENCES}

[1] Dey KK. An Introduction to Plant Tissue Culture, New central book agency (P) Ltd., Calcutta, India 1997, pp. 35-44.

[2] Narayanswamy S. Plant Cell and Tissue Culture, Tata McGrawHill Education, New Delhi, India 1994, pp. 22-51.

[3] Chatterji N, Rastogi RP, Dhar ML. Chemical examination of Bacopa monnieria Wettst: Part 1 - Isolation of chemical constituents. Indian J Chem. 1963; 1: 212-215.

[4] Asolkar LV, Kakkar KK, Chakre OS. Second Supplement to Glossary of Indian Medicinal Plants with active Principles (Part I), CSIR, New Delhi, India 1992, pp. 112-113.

[5] Nadkarni KM. The Indian Materia Medica I, Popular Prakashan, Mumbai, India 1982, pp. 624-625.
[6] Sala AV. Indian Medicinal Plants, Orient Longman, Kottakkal, India 1994, pp. 235-236.

[7] Mishra SK, Tiwari KN, Shivna PL, Mishra AK. Micropropagation and Comparative Phytochemical, Antioxidant Study of Bacopa monnieri (L.) Pennell. Res J Pharm Biol Chem Sci. 2015; 6(6): 902-912.

[8] Ambasta SP. Wealth of India Raw Materials, Vol. 2:B. Council of scientific and Industrial Research, New Delhi, India 1988, pp. 23-24.

[9] Jain SK, DeFilipps RA. Medicinal Plants of India, Vol. 2. Reference Publication Inc., Michigan, USA 1991, pp. 556-557.

[10] Soundararajan T, Karrunakaran CM. Micropropagation of Bacopa monnieri through protoplast. Asian J Biotechnol. 2011; 3(2): 135-152.

[11] Heble MR. Production of secondary metabolites through tissue culture and its prospects for commercial use. In: Islam AS. editor. Plant Tissue Culture, Oxford and IBH Publishing Company Pvt. Ltd., New Delhi. 1997, pp. 161-168

[12] George J, Ravishankar GA. Harnessing high value metabolites from plant cells. Ind J Pharm Educ. 1996; 30: 120-130.

[13] Fowler HW. Extraction. In: Carter SJ. editor. Cooper and Gunn's Tutorial Pharmacy, $6^{\text {th }}$ ed. CBS Publishers and Distributors, New Delhi. 1986, pp. 251-261.

[14] Yelne MB, Borkar GB, Sharma PC. In vitro propagation of Brahmi - Bacopa monnieri (L.) Pennell. Bull Medico - Ethno - Bot Res 1997; 18(3 - 4): 45-50.

[15] Stahl E. Thin Layer Chromatography, second ed., SpringerVerlag Berlin Heidelberg, Germany 1969, pp. 904-905.

[16] Srivastava VK, Srivastava KK. Introduction to Chromatography, S. Chand and Company Ltd., Delhi, India 1991, pp. 8-32.

[17] Sethi PD. High-performance Thin Layer Chromatography, CBS Publisher and distributors, New Delhi, India 1996, pp. 4-28.

[18] Narayana DBA, Agarwal S, Luthra SK, Srinivas NS. A HPTLC method for the quantitative analysis of vasicine in Adhatoda vasica. Indian Drugs. 1995; 32: 583-586.

[19] Chauhan SK, Singh BP, Agrawal S. Determination of Embelin from Embelia ribes by high performance thin layer chromatography. Indian Drugs. 1999; 36: 41-43. 